\title{
Psychosocial and Spiritual Needs of Dying Patients from the Perspective of the Nurse and Length of Professional Practice (Original Research)
}

\section{Andrasi (Imrich Andrasi)1,2, V. Littva (Vladimir Littva)2, M. Sichman (Marek Sichman)2, L. Novakova (Lada Novakova)1,3}

${ }^{1} \mathrm{PhD}$. Student, St. Elizabeth University, Bratislava, SK

${ }^{2}$ Faculty of Health, CU Ruzomberok, SK

${ }^{3}$ VSP Jihlava, CZ

\section{E-mail address:}

littva.vladimir@gmail.com

\section{Reprint address:}

Vladimir Littva

Faculty of Health

Nam A. Hlinku 48

03401 Ruzomberok

SK

Suource: Clinical Social Work and Health Intervention

\section{Reviewers:}

Daniel J. West

University of Scranton, Department of Health Administration and Human Resources, USA

Stefan Krajcik

Geriatric Department, Slovak Medical University, SK

\section{Key words:}

Spiritual Needs. Nurses. Midwives. Length of Practice. Dying Patients.

\section{Publisher:}

International Society of Applied Preventive Medicine i-gap

CSWHI 2017; 8(4): 7 - 16; DOI 10.22359/cswhi_8_4_01 @ 2017 Clinical Social Work and Health Intervention

\section{Abstract:}

Objective: The aim of our research was to find out correlation between length of practice in Nurses and Midwives and length of practice in satisfaction of spiritual needs of dying patients. 
Design: Project study.

Participants: 433 respondents (43 were men and 390 women). In terms of jobs the majority was of Nurses and Midwives 385 (86.6\%). The most numerous age group was between $35-44$ years $(40.9 \%), 25$ to 34 years $(24 \%), 45-54$ years $(23.6 \%)$, under $20(4.6 \%)$ and above 5530 participants $(6.9 \%)$. Length of experience: The largest group 1021 years of practice $(32.8 \%), 22-31$ years $(25.9 \%)$, 5-9 $(15.5 \%)$, under $5(12.7 \%)$ and over 32 years practice $(13.2 \%)$.

Methods: Standardized questionnaires SNAP (Spiritual Needs Assessment for Patients) and SCCS (Spiritual Care Competence Scale) analyzed by descriptive characteristics for variables and subsequent testing of normality. Due to the sample size was used the Kolmogorov-Smirnov test (KS-test). We evaluated the correlation by using SPSS 22 Parametric Pearson Correlation Coefficient with a significance level of $\mathrm{p}<0.01$ and $\mathrm{p}<0.05$.

Results: We evaluated the intrinsic reliability of SNAP using the Cronbach Alpha coefficient for SNAP - Spiritual needs is $>0.900$ in the whole set, which we interpret as a high degree of elemental credibility, respectively internal consistency of the questionnaire. In the SNAP Psychosocial needs $>0.750$, which also interferes with the high level of reliability at the item level. As for interpolar correlations and also the correlation between individual items and the total SNAP subtracted score, we found that the Spearman correlation coefficient between items and SNAP scores are in the range of $0.608-0.787$ which is a strong to very strong correlation. The correlation is significant at a level of Sig. $\mathrm{p}<0.01$. Length of practice - The correlation of the value (Spearman's correlation coefficient) $\rho=0.105$ (Sig. $p<0.05$ ) is directly related to attitudes of Nurses and Midwives. There is a statistically significant relationship between the length of practice and SCCS subclass - professionalization and quality improvement of spiritual care $(p=0.121$; Sig. $\mathrm{p}<0.05)$.

Conclusion: The project study shows that important role in the approach to dying patients and their spiritual needs plays not only to good preparation in school, but also personal experience that Nurses and Midwives acquire during their professional practice.

\section{Introduction and Aim}

The Nurse has an irreplaceable role in nursing processes during the dying period of the patient. She/he is part of a multidisciplinary team requiring high professionalism, professional maturity and good communication ability (Kelnarova, 2007). An important prerequisite for the work of Nurses in the field of palliative nursing care is personal

maturity and certain features of character, of which the most important are ability of self-control and patience. The essence of nursing care for a dying patient is to ensure an adequate quality of life that greatly affects the understanding of human existence and the meaning of human life. The Nurse in a process of caring for the dying patient 
is the person who provides care and treatment. Her/his main task is to saturate the patient's needs according to priorities. Usually we say that it should be a priority to satisfy the biological needs which we consider to be primary; without which it is impossible to effectively meet the psychosocial and spiritual needs. However, this is not always the case. In the dying, it could be the higher needs including spiritual needs. Experience from practice plays an important role in care for a dying patient. Positive death experiences are associated with absence of patient pain, dyspnea, anxiety, or agitation and the presence of spiritual, psychological, and culturally appropriate care for the patient and family (Bennett, Proudfoot, 2016).

From time immemorial, spiritual care has played an important role in the care of the sick and subsequently in nursing care. In the past, the development of the company influenced by certain ideology has come to a halt for a period; but not forever. We can assume that spirituality is a general characteristic of a person (Rican, 2010). Spirituality and spiritual needs have a particular importance in the terminal stage of disease. Satisfying spiritual needs helps patients to be more tolerable to cope with suffering. Satisfying spiritual needs is of great importance for the sick person (Zrubakova, Herinkova, 2015).

With regard to all the needs of the dying, we should not forget to integrate them into a holistic view of a human. On the other hand, we should not forget the fact that each person is a specific identity which from a psychological point of view can be understood as self-perception and self-awareness; perception of one's own uniqueness and difference from others (Hartl, Hartlova, 2004).

Through an interview with the patient, the Nurse has the opportunity to know the patient's spiritual needs and then to set the goal of meeting these needs. The assessment of spiritual needs must be very gentle, which is one of the most important principles of their satisfaction. Spiritual care must be planned as well as satisfying other needs of the patient. The most important in meeting the spiritual needs is the quality of interpersonal relations. The Sister often becomes the main person in the process of establishing such relationships in the workplace (Kelnarova, 2007).

In current practice, there have been developed standards for the satisfaction of biological needs but there is a lack of standards for the satisfaction of spiritual needs (Prasilova, 2009). The spiritual needs of the dying patient are related especially with his/her accompanying spiritual experience. Spiritual care can be perceived by such a patient as a need for understanding their own lives, suffering and death. The spirituality is perceived by the dying patient as the acceptance of the afterlife; the forgiveness, the communication with God; but also the hope.

Kelnarova (2007) defined important principles for practice in the satisfaction of spiritual needs:

- Spiritual care requires trust and mutual support.

- Spiritual care is part of all the activities we do for and with the dying.

- Spiritual care requires an assessment of the current dying situation.

- We do not press on a dying person; during conversation we will show interest in him.

Modern nursing perceives dying as a whole range of medical problems that need to be identified and need to be dealt with. The idea of a good dying comes as alien to many people because they do not realize that death can involve more than physical pain and tragedy. The real experience of dying cannot be perceived purely from the medical point of view. As long 
as we support the human dimension of the dying, the process of dying can become as deep and intimate as the birth of a child (Byock, 2013).

Spiritual needs have a close relationship with the search for meaning of life and death; they cannot be limited to religiosity, although in most cases we understand them in this sense. We can define spiritual needs as a means of achieving welfare (Cicha, 2010).

Howard Clinebell believed that humans have seven spiritual hungers in common. As you read through them, consider whether you recognize any of these spiritual needs in yourself. Are there particular areas of "spiritual hunger" in your life that need more attention than others?

Specifically, Clinebell felt that human beings long for seven spiritual needs:

- Experience the healing and empowerment of love-from others, self, and an ultimate source.

- Experience renewing times of transcendence; expansive moments beyond immediate sensory spheres.

- Have vital beliefs that lend meaning and hope in the midst of losses, tragedies, and failures.

- Have values, priorities, and life commitments centered in issues of justice, integrity, and love to provide guidance for personally and socially responsible living.

- Discover and develop inner wisdom, creativity, and love of self.

- Develop a deepening awareness of oneness with other people, the natural world, and all living things.

- Have spiritual resources to help heal grief, guilt, resentment, unforgiveness, self-rejection, and shame and deepen experiences of trust, self-esteem, hope, joy and love of life. (Clinebell, 2012).
Satisfaction of spiritual needs involves salvaging not only the sick part of the human body, but also with the sick/dying human and subsequently with relatives/ survivors. Nurses act on them by their professional interventions, as well as all their personality; relationship; degree of professional qualities; level of competence; professional adaptation (Moraucikova, 2015).

The aim of our research was to find any correlation between the length of practice in Nurses and Midwives and the length of practice in satisfaction of spiritual needs of dying patients. We have worked on this project for three years in Slovakia.

Research sample consisted of a total 433 respondents, of which 43 were men (9.9\%) and 390 were women (90.1\%). In terms of jobs, the majority w were Nurses $375(86.6 \%)$; other positions are represented several times lower: paramedics 28 (6.5\%); medical assistants 14 (3.2\%); Midwives 10 $(2.3 \%)$; sanitarists-caregivers $6(1.4 \%)$. The most numerous age group was between 35 44 years $(40.9 \%) ; 25$ to 34 years $(24 \%)$; 45 54 years $(23.6 \%)$; under $2020(4,6 \%)$ and above 5530 participants (6.9\%). Length of experience was also similarly represented. The largest group 10-21 years of practice (32.8\%); 22-31 years $(25.9 \%)$; 5-9 (15.5\%); under $5(12.7 \%)$ and over 32 years practice $(13.2 \%)$. In terms of work most respondents were working at standard treatment unit/ wards at the hospital (36.5\%); in outpatient casualty treatment departments $(24.5 \%)$; independent ICU (18\%); social facilities and HNCA - home nursing care agency (15.2\%); Department of Anesthesiology; IM; operating theaters $5(1,2 \%)$; education and management 5 respondents $(1.2 \%)$; other workplaces reported $2.2 \%$ of respondents. Research output as variable is also the religion represented. No religion is a set of $15 \%$; $77.4 \%$ of respondents are believers; others $7.6 \%$ did not care about religion (Table 1). 
Table 1: Frequency table of categorical variables: gender, age, position, workplace, length of practice, faith in the whole sample.

\begin{tabular}{|c|c|c|c|}
\hline & & $\begin{array}{l}\text { Absolute } \\
\text { number }\end{array}$ & $\%$ \\
\hline \multirow[t]{2}{*}{ Gender } & Masculine & 43 & 9.9 \\
\hline & Feminine & 390 & $90 ; 1$ \\
\hline \multirow[t]{5}{*}{ Age } & $<25$ years & 20 & 4.6 \\
\hline & $25-34$ years & 104 & 24 \\
\hline & $35-44$ years & 177 & 40.9 \\
\hline & $45-54$ years & 102 & 23.6 \\
\hline & $55-64$ years & 30 & 6.9 \\
\hline \multirow[t]{5}{*}{ Work position } & Nurse & 375 & 86.6 \\
\hline & Midwife & 10 & 2.3 \\
\hline & Paramedics & 28 & 6.5 \\
\hline & Sanitarists-caregivers & 6 & 1.4 \\
\hline & Healthcare assistant & 14 & 3.2 \\
\hline \multirow[t]{8}{*}{ Work place } & Standard treatment unit / the wards at the hospital & 158 & 36.5 \\
\hline & ICU & 78 & 18 \\
\hline & Operating theaters & 5 & 1,2 \\
\hline & Anesthesiology and IM & 5 & 1,2 \\
\hline & Casualty treatment departments & 106 & 24.5 \\
\hline & Social facilities and HNCA & 66 & 15.2 \\
\hline & Others & 10 & 2.2 \\
\hline & Education and Management & 5 & 1.2 \\
\hline \multirow[t]{5}{*}{$\begin{array}{l}\text { Length of } \\
\text { practice }\end{array}$} & $<5$ years & 55 & 12.7 \\
\hline & $5-9$ years & 67 & 15.5 \\
\hline & $10-21$ years & 142 & 32.8 \\
\hline & $22-31$ years & 112 & 25.9 \\
\hline & $>32$ years & 57 & 13.2 \\
\hline \multirow[t]{3}{*}{ Faith } & Believers & 335 & 77.4 \\
\hline & No religion & 65 & 15 \\
\hline & Not given & 33 & 7.6 \\
\hline
\end{tabular}

In Table 2, is information of categorical variables in the groups of Nurses and Midwives, which are the most numerous - 367 respondents formed of $95.3 \%$ women and
4.7\% men. Other evaluated variables are similarly represented as in the entire file, so we will not interpret them in the text (Table 2). 
Table 2: Frequency table of categorical variables: gender, age, position, workplace, length of practice, faith in Nurses and Midwives.

\begin{tabular}{|c|c|c|c|}
\hline & & $\begin{array}{l}\text { Absolute } \\
\text { number }\end{array}$ & $\%$ \\
\hline \multirow[t]{2}{*}{ Sex } & Masculine & 18 & 4.7 \\
\hline & Feminine & 367 & 95.3 \\
\hline \multirow[t]{5}{*}{ Age } & $<25$ years & 7 & 1.8 \\
\hline & $25-34$ years & 87 & 22.6 \\
\hline & $35-44$ years & 162 & 42.1 \\
\hline & $45-54$ years & 99 & 25.7 \\
\hline & $55-64$ years & 30 & 7.8 \\
\hline \multirow[t]{2}{*}{ Work position } & Nurse & 375 & 97.4 \\
\hline & Midwife & 10 & 2.6 \\
\hline \multirow[t]{8}{*}{ Work Place } & Standard treatment unit / the wards at the hospital & 142 & 36.9 \\
\hline & ICU & 75 & 19.5 \\
\hline & Operating theaters & 5 & 1.3 \\
\hline & Anesthesiology and IM & 5 & 1.3 \\
\hline & Casualty treatment departments & 82 & 21.3 \\
\hline & Social facilities and HNCA & 65 & 16.9 \\
\hline & Others & 7 & 1.8 \\
\hline & Education and Management & 4 & 1 \\
\hline \multirow[t]{5}{*}{$\begin{array}{l}\text { Length of } \\
\text { practice }\end{array}$} & $<5$ years & 41 & 10.6 \\
\hline & $5-9$ years & 49 & 12.7 \\
\hline & $10-21$ years & 129 & 33.5 \\
\hline & $22-31$ years & 110 & 28.6 \\
\hline & $>32$ years & 56 & 14.5 \\
\hline \multirow[t]{3}{*}{ Faith } & Believers & 298 & 77.4 \\
\hline & No religion & 59 & 15.3 \\
\hline & Not given & 28 & 7.3 \\
\hline
\end{tabular}

\section{Methods}

To obtain relevant data, we used standardized questionnaires SNAP (Spiritual Needs Assessment for Patients) and SCCS (Spiritual Care Competence Scale). The obtained data were analyzed by descriptive characteristic for variables and subsequent testing of normality. Due to the sample size was used the Kolmogorov-Smirnov test (KS-test). We evaluated the correlation by using SPSS 22 Parametric Pearson Correlation Coefficient with a significance level of $p<0.01$ and $p$ $<0.05$.

\section{Results}

In our survey, we achieved the following results: characteristics for variables obtained 
through the SNAP questionnaires (Psychosocial needs and Spiritual needs) and the SCCS.

Table 3 gives descriptive characteristics for SNAP variables - Psychosocial needs, SNAP - Spiritual needs and SCCS for Nurses and Midwives. For the interpretation of values, the same expressions apply as for the whole research file. We would only point to the minimum value in SCCS, which is 45 points for Nurses and Midwives, and 31 points for the whole sample.

In interpreting Kolmogor-Smirnov's normality test, in the group of Nurses and Midwives, we can notice that even in the SCCS variable significance was achieved Sig. $\mathrm{p}<0.05$, thus rejecting the supposition of normal distribution in this variable (Table 4).

Table 3: Descriptive characteristic scales SNAP - Psychosocial needs, SNAP Spiritual needs and SCCS in Nurses and Midwives.

\begin{tabular}{|l|l|l|l|}
\hline & SNAP Psychosocial needs & SNAP Spiritual needs & SCCS \\
\hline $\mathrm{N}$ & 385 & 385 & 385 \\
\hline Average & 16,29 & 42,02 & 101,45 \\
\hline Median & 17 & 42 & 102 \\
\hline Modus & 17 & 47 & 95 \\
\hline Standard Deviation & 2,78 & 7,09 & 16,95 \\
\hline Obliquity & $-0,58$ & $-0,71$ & $-0,33$ \\
\hline Sharpness & $-0,15$ & 0,42 & $-0,27$ \\
\hline Minimum & 7 & 15 & 45 \\
\hline Maximum & 20 & 52 & 135 \\
\hline $1^{\text {st }}$ quartile & 14 & 37,5 & 90 \\
\hline $3^{\text {rd }}$ quartile & 19 & 48 & 115 \\
\hline
\end{tabular}

Table 4: Results of normality testing of the SNAP and SCCS (Kolmogorov-Smirnov's test) in Nurses and Midwives.

\begin{tabular}{|l|l|l|l|}
\hline & \multicolumn{3}{|l|}{ Kolmogorov-Smirnov } \\
\hline & Statistic & df & Sig. \\
\hline SNAP - Psychosocial needs & .120 & 385 & .000 \\
\hline SNAP - Spiritual needs & .091 & 385 & .000 \\
\hline SCCS & .048 & 385 & .035 \\
\hline
\end{tabular}


We evaluated the intrinsic reliability of SNAP - Psychosocial needs and SNAP Spiritual needs using the Cronbach Alpha coefficient. As can be seen in Table 5, the value of the coefficient for SNAP - Spiritual needs is greater than 0.900 in the whole set, which we interpret as a high degree of elemental credibility, respectively internal consistency of the questionnaire. None of the 13 items reduces this value, so we consider the items to be consistently saturation to that sub-scale. In the SNAP - Psychosocial needs, the calculated coefficient is higher than 0.750 , which also interferes with the high level of reliability at the item level. None of the 5 items alter the Alpha coefficient value and all share the same score on the overall score of the sub-scale. correlation is significant at a level of Sig. $p<0.01$. Interpolar correlations representing item relationships have a statistical significance of Sig. $\mathrm{p}<0.001$.

We have evaluated the correlation between used methodologies and the subscales. Because of the sample size, we used the parametric Pearson correlation coefficient (although SCCS and SNAP sub-scales do not have normal distribution). In Table 6 we can see that there is a weak positive relationship between the SCCS score and the SNAP - Psychosocial needs $(r=0.270$, Sig. $\mathrm{p}<0.001$ ), and between the SCCS score and the SNAP - Spiritual needs is a moderate positive relationship $(r=0.366$; Sig. $\mathrm{p}<0.001)$.

Table 5: Cronbach Alpha coefficient for SNAP.

\begin{tabular}{|l|l|l|}
\hline & SNAP - Spiritual needs & SNAP - Psychosocial needs \\
\hline Whole sample $(\mathrm{N}=433)$ & 0.921 & 0.780 \\
\hline
\end{tabular}

As for interpolar correlations and also the correlation between individual items and the total SNAP subtracted score, we found that the Spearman correlation coefficient between items and SNAP scores - Psychosocial needs are in the range of $0.684-0.787$, which is a strong to very strong correlation. The correlation is significant at a level of Sig. $\mathrm{p}<0.01$. Relationships between items and SNAP scores - Spiritual needs reach Spearman's correlation coefficient from $0.608-0.778$, which we interpret as strong to very strong correlations. The
Further data in Table 6 tells about the relationships between SNAP - Psychosocial needs, SNAP - Spiritual needs and SCCS sub-scales. All identified relationships can be interpreted as weak positive correlations (in the range of 0.1 to 0.3 ) except for the relationship between SNAP - Spiritual needs and SCCS - Professionalization and quality improvement of spirituality care $(r=0.321$; Sig. $\mathrm{p}<0.001)$ and SNAP - Spiritual needs and SCCS - Personal support and advice to the patient $(r=0.301$, Sig. $\mathrm{p}<0.001)$, which we formally consider to be moderate.

Table 6: Correlations between SNAP sub-scales and SCCS sub-cales (Pearson correlation coefficients).

\begin{tabular}{|l|l|l|l|}
\hline & & $\begin{array}{l}\text { SNAP - Psychosocial } \\
\text { needs }\end{array}$ & $\begin{array}{l}\text { SNAP - Spiritual } \\
\text { needs }\end{array}$ \\
\hline SCCS & $\mathrm{r}$ & $.270^{* *}$ & $.366^{* *}$ \\
& Sig. & 0.000 & 0.000 \\
\hline & $\mathrm{N}$ & 433 & 433 \\
\hline
\end{tabular}




\begin{tabular}{|c|c|c|c|}
\hline \multirow[t]{3}{*}{ Attitude to patient's spirituality } & $\mathrm{r}$ & $.170 * *$ & $.151 * *$ \\
\hline & Sig. & 0.000 & 0.002 \\
\hline & $\mathrm{N}$ & 433 & 433 \\
\hline \multirow[t]{3}{*}{ Communication } & $\mathrm{r}$ & $.208 * *$ & $.213 * *$ \\
\hline & Sig. & 0.000 & 0.000 \\
\hline & $\mathrm{N}$ & 433 & 433 \\
\hline \multirow{3}{*}{$\begin{array}{l}\text { Assessment and implementation of } \\
\text { spiritual care }\end{array}$} & $r$ & $.212 * *$ & $.282 * *$ \\
\hline & Sig. & 0.000 & 0.000 \\
\hline & $\mathrm{N}$ & 433 & 433 \\
\hline \multirow[t]{3}{*}{ Request for consent } & $\mathrm{r}$ & $.232 * *$ & $.299 * *$ \\
\hline & Sig. & 0.000 & 0.000 \\
\hline & $\mathrm{N}$ & 433 & 433 \\
\hline \multirow{3}{*}{$\begin{array}{l}\text { Personal support and advice to the } \\
\text { patient }\end{array}$} & $\mathrm{r}$ & $.193 * *$ & $.301 * *$ \\
\hline & Sig. & 0.000 & 0.000 \\
\hline & $\mathrm{N}$ & 433 & 433 \\
\hline \multirow{3}{*}{$\begin{array}{l}\text { Professionalization and quality } \\
\text { improvement of spirituality care }\end{array}$} & $\mathrm{r}$ & $.217 * *$ & $.321 * *$ \\
\hline & Sig. & 0.000 & 0.000 \\
\hline & $\mathrm{N}$ & 433 & 433 \\
\hline
\end{tabular}

** The correlation is significant at a level of $\mathrm{p}<0.01$

Length of practice - The correlation of the value (Spearman's correlation coefficient) $\rho=0.105$ (Sig. $\mathrm{p}<0.05)$ is directly related to attitudes of Nurses and Midwives (the longer the practice, the slightly higher the attitude toward patient spirituality). With longer practice, healthcare professionals are increasing their ability to communicate with patients (SCCS). There is a statistically significant relationship between the length of practice and SCCS subclass - professionalisation and quality improvement of spiritual care $(p=0.121$; Sig. $p<0.05)$. With the increasing length of practice, the professionalization and the improvement of the quality of care for spirituality are increasing.

Age slightly correlates with the SCCS score $(p=0.137$, Sig. $p<0.01)$, and its subscales - Communication ( $\mathrm{p}=0.104$, Sig., $\mathrm{p}<0.05$ ), Assessment and Implementation of Spiritual Care $(p=0.165 ; p<0.01)$. Also important are the relationship between Age and Attitude to Patient Spirituality and Age and Personal Support and Counseling to a patient with a value of $\rho=0.100$, but this is interpreted as a very weak correlation and therefore no relevant context can be discussed.

Length of practice, in addition to the above results, correlates significantly and positively with the overall SCCS score ( $p$ $=0.185$; Sig. $\mathrm{p}<0.001)$ and with all other SCCS subclasses.

\section{Conclusion}

Nurses and Midwives are commonly confronted with death, and their perception of death should be on a professional level. In the process of disease and dying, staff and patients are brought into interaction. In today's modern nursing care, high emphasis 
is placed on the quality of care provision and humanization, so the Nurse must be flexible and have full responsibility for her work, which stems from her competencies.

An important role in the approach to dying patients and their spiritual needs plays not only to good preparation in school, but also personal experience that Nurses and Midwives acquire during their professional practice. It is important that professionals be properly prepared when patients need this communication. An evidence-based training intervention could provide such preparation (Henoch et all., 2015)

Care of dying patients is one of the hardest jobs in the healthcare sector, as it is not only the physical site of the Nurses, but especially their psyche. The spiritual needs of a dying person can sometimes be overlooked in the busyness of physical care. However, for those experiencing it, spiritual distress is very real (Hlinkova, Moraučíková, 2014). While Nurses most often find a deficiency in the area of biological needs that are primary for humans, we are increasingly confronted with the fact that the dying patient has as priority his spiritual needs.

\section{References}

1. BENNETT R, PROUDFOOT J (2016) What Does the Staff Think?: Factors Associated With Clinical Staff Perceptions of What Constitutes High-Quality Dying and Death at a Tertiary Pediatric Hospital, In: Journal of Hospice \& Palliative Nursing. Lippincott Williams \& Wilkins, Philadelphia, Volume: 18 Issue: 5 Pages: 470-476.

2. BYOCK I (2013) Good dying. Praha: Vysehrad, 2013, $328 \mathrm{p}$.

3. CICHA M (2010) Dying and Death from a Multicultural Perspective - A Basis for Health and Social Work. In: Applied ethics in social work and other assisting professions. Proceedings of the International Scientific Conference. Bratislava: High School of Health and Social Work st. Elizabeth, 2010, p. 35-44.

4. CLINEBELL H (2012) Basic Types of Pastoral Care \&Counseling:Resources for the Ministry of Healing and Growth. Abingdon Press, 2012, $520 \mathrm{p}$.

5. HARTL P, HARTLOVA, H (2004) Psychological Dictionary. Praha: Portal, 2004, 774 p.

6. HENOCH I, STRANG S, BROWALL M et al. (2015) Development of an existential support training program for healthcare professionals, In: Palliative \& Supportive Care, New York, Cambridge University Press, Volume: 13 Issue: 6 Pages: 17011709.

7. HLINKOVA S, MORAUCIKOVA E (2014) Spirituality and Spiritual Needs in the Palliative Care. In: Satisfying spiritual needs of dying. Brno, Tribun, p. 31-52.

8. KELNAROVA J (2007) Tanatology in Nursing. Brno: Littera, 2007, 109 p.

9. MORAUCIKOVA E (2015) Multidisciplinary care about remainder. Logos Polytechnikos. Nr. 2, p. 82-87.

10. PRASILOVA M (2009) Spiritual needs of hardly ill / dying. In: HATOKOVA M et al. Managing the sick and dying. Bratislava: Don Bosco, 2009, 215 p., p. 105-126.

11. RICAN P (2010) Spirituality at the center of the personality structure. In: BLATNY M Psychology of personality. Praha: Grada Publishing, p. 225-238.

12. RIDOSKO J, STORCEL M (2013) Optimizing the treatment of heel bone fractures. 2. the results of the treatment. In Medical Horizon, ISSN 0457-4214. 2013, 62, 3, s. 95-101.

13. ZRUBAKOVA K, HERINKOVA A (2015) The Importance of Spirituality in Oncology Patients. In: Assessing the symptoms and spiritual needs of patients in palliative care. Bratislava, SAP, p. 94 -114. 